\title{
Review on 3D printed concrete as structural beam members by Pamuda Pudjisuryadi
}

Submission date: 05-Jan-2021 11:49AM (UTC+0700)

Submission ID: 1483171511

File name: udjisuryadi_2020_IOP_Conf._Ser._Mater._Sci._Eng._930_012045.pdf (1.16M) Word count: 2581

Character count: 14407 
PAPER • OPEN ACCESS

Review on 3D printed concrete as structural beam members

2

To cite this article: P Pudjisuryadi et al 2020 IOP Conf. Ser.: Mater. Sci. Eng. 930012045

View the article online for updates and enhancements.

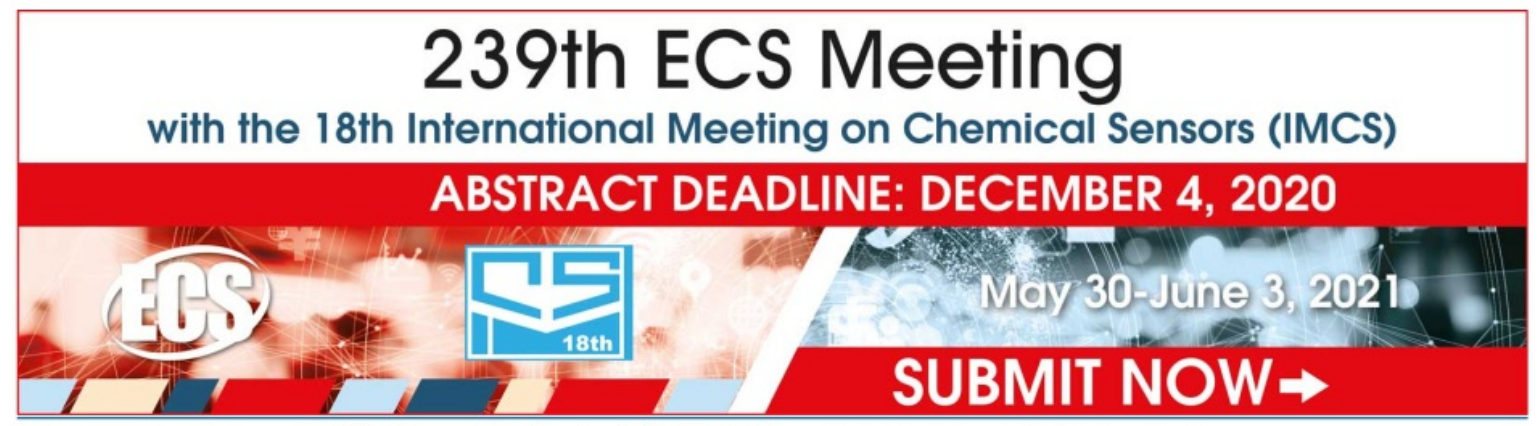

This content was downloaded from IP address 36.85 .23 .206 on 02/12/2020 at 00:46 


\title{
Review on 3D printed concrete as structural beam members
}

\author{
P Pudjisuryadi ${ }^{1}$, A Antoni ${ }^{1}$ and $\mathrm{J} \mathrm{Chandra}^{1}$ \\ ${ }^{1}$ Civil Engineering Department, Petra Christian University, Siwalankerto 121-131, Surabaya, \\ Indonesia
}

\begin{abstract}
Recently, Three-Dimensional Concrete Printing (3DCP) has gained its popularity as construction material. It offers several advantages over conventionally casted concrete such as absence of formwork, reduction of construction equipment transportation, greater safety, reduction of labour cost, and many others. However, the technology also comes with many challenges. Researches in this area can be classified into two issues which are fresh and hardened states of the printed concrete. Investigation of fresh concrete focuses on the optimal design of rheological properties which determines the pumpability, extrudability, and buildability. While mechanical properties of hardened 3DCP are usually investigated by adopting standard tests for conventionally casted concrete. However, due to the complexity of printing process, it is often that 3DCP behaviours cannot be predicted by its mechanical properties obtained from the tests. This paper reviews some studies done by others to highlight potential manufacturing process related weak points of $3 \mathrm{DCP}$ as structural beam members.
\end{abstract}

\section{Introduction}

In this rapidly growing technology era, one concrete construction method has been relatively favoured to be researched and developed, namely the Three-Dimensional Concrete Printing (3DCP) [1]. 3DCP is a technology to build concrete by extruding plastic mortar against a casting bed through a nozzle opening which movement is controlled by a robotic arm system [2]. The extruded mortar filaments will shape certain desired 3D body of concrete by adding subsequent layers on top of previous ones, without the use of any formwork. Aside from freedom of formwork, 3DCP has many other advantages, some of them are reduction of construction equipment transportation, reduction of construction time and expenses, greater safety, and saving labour cost [3]. However, to fully utilize those benefits, complexity of 3DCP process rises many challenges. Characteristic of both fresh and hardened states of the concrete should be well investigated.

Fresh concrete for 3DCP should possesses good rheological properties such as pumpability, extrudability, and buildability [4]. Those can be achieved if the mix design of the fresh concrete is well collaborated with the chosen printing process. In other words, different printing process may require different mix concrete design for a successful 3DCP. Consideration of the fresh concrete itself may include the initial yield strength and its development, and the setting time. The yield stress should be low enough that the concrete can be pumped and extruded, but its strength development should be quick enough that the extruded layer could sustain the load from the subsequent layers above. Setting time should be designed that the fresh concrete remains workable during printing process. Logically, in the design process of those properties, the printing process should already be included. Planar path of each layer, relative height of subsequent concrete layer, and speed of printing head (deposition rate) should be balanced that the extruded material could remain stacked, bonded in layers and sustain the weight of other layers that are deposited on top. This challenging relationship between fresh concrete and the manufacturing process of 3DCP has attracted many researchers [5-6].

(c) (i) Content from this work may be used under the terms of the Creative Commons Attribution 3.0 licence. Any further distribution of this work must maintain attribution to the author(s) and the title of the work, journal citation and DOI. 
4th International Conference on Civil Engineering Research (ICCER 2020)

IOP Publishing

IOP Conf. Series: Materials Science and Engineering 930 (2020) 012045 doi:10.1088/1757-899X/930/1/012045

The next thing that becomes the concern of engineers after successfully constructs 3DCP without collapse, is the quality of the resulting hardened concrete. Commonly, researchers adopt standard tests of conventionally casted concrete to measure the quality of hardened 3DCP. Le et al. [7] conducted experiments that can give some idea about 3DCP hardened properties. Due to gently vibrated hopper and small pressure during extrusion, good 3DCP tends to have higher density than that of conventional concrete. However, it should be noted that the higher density observed were measured from specimens which were cut from 3DCP slab which was relatively easy to print. Compressive strength showed variations (72 $\mathrm{MPa}$ to $102 \mathrm{MPa}$ ) if the test samples were cut from different printing specimen, even with the same fresh concrete. Specimens which were cut from printed slab showed higher strength (and lower anisothropic behaviour) than that which were cut from curvy printed shapes (more difficult printing process). From flexural strength test, it was observed that lower layers tended to have higher strength since they had higher density and lower w/c ratio. Inter-layer tensile bond strength highly depended on the gap time between layers. Gap time is the time interval of printing process between two subsequent layers at the same position. It can be concluded that due to the nature of printing process, it is logical that the hardened 3DCP properties is highly anisotrophic. Bonding strengths between adjacent layers and filaments play very important role in determining the quality hardened concrete because they are potential weak points of $3 \mathrm{DCP}$. Horizontally, the mechanical properties in the direction of filament path is different to its perpendicular direction. Vertically, the mechanical properties of different layers are also different since lower layers have higher density due to the pressing weights of layers above them.

Furthermore, applicability of 3DCP as structural members raises challenges for engineers even more. There are many things should be considered for assessing the hardened 3DCP quality, which may not be necessary for conventionally casted concrete. Adopting standard assessment for conventionally casted concrete is not enough to give accurate information of how good a 3DCP is. Structural member can show highly non-linear behaviour from the very beginning, which cannot be predicted by standard tests of concrete material. Some reviews of this concern are presented in this paper.

\section{Research significance}

This paper raises awareness that if 3DCP is to be used as structural members, investigation of 3DCP hardened mechanical properties alone may not be enough to accurately predict the structural performance. Once 3DCP is used to construct certain structural member, the behaviour of the member is not as simple as conventionally casted concrete. Premature non-linear behaviour may arise which is not the case in conventionally casted concrete structural member.

\section{Research on 3DCP as structural beam member}

The main advantage of 3DCP that complex body forms can be made, has opened opportunities for concrete industry. With 3DCP technology, final weight of structural beam member can be reduced by manufacturing complex shape (introducing hollows) with proper analysis to guarantee the adequacy of the intended application (topology optimization). For example, a beam member can be printed to form a truss like shape (Figure 1), instead of classical prismatic shape. However, to fully utilize this advantage, some manufacturing challenges have to be overcome. Efforts done by others are presented in the following subsections.

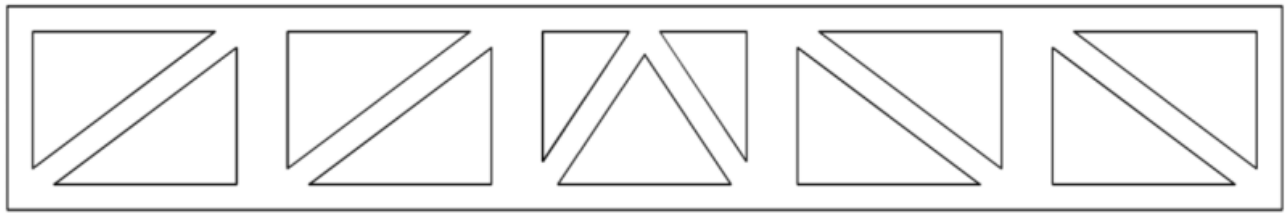

Figure 1. Truss like shape structural beam. 
4th International Conference on Civil Engineering Research (ICCER 2020)

IOP Publishing

IOP Conf. Series: Materials Science and Engineering 930 (2020) 012045 doi:10.1088/1757-899X/930/1/012045

\subsection{Non-Segmented 3DCP structural beam}

Al-Chaar et al. [8] conducted experiment on truss like 3DCP beams. The beam was 3D printed as one body at one time. Tension reinforcement bars were embedded inside the bottom horizontal chord. A cyclic flexural test was conducted on the beams. It can be seen from the force-displacement relationship (Figure 2), that the beam stiffness started very low and then slightly increased. This behaviour is not normal. It cannot be explained by the material properties alone. There are potential weakening points in 3DCP members in its filament to filament and layer to layer bonding. A numerical model ling by using SAP2000 was done by authors to predict the behaviour of the beams tested by Al-Chaar et al. [8] if treated as conventional homogeneous concrete without considering the weakening of bonding strength. The resulting load-displacement curve is presented in Figure 3. It can be observed that the analytical model possesses stiffness much higher than that of the tested 3DCP beam (Figure 2). This shows that, one should be aware of the potential degradation of 3DCP structural beams due to the potential weakening of the bonding. More complex printing paths will introduce more variation of age differences and qualities between connections.

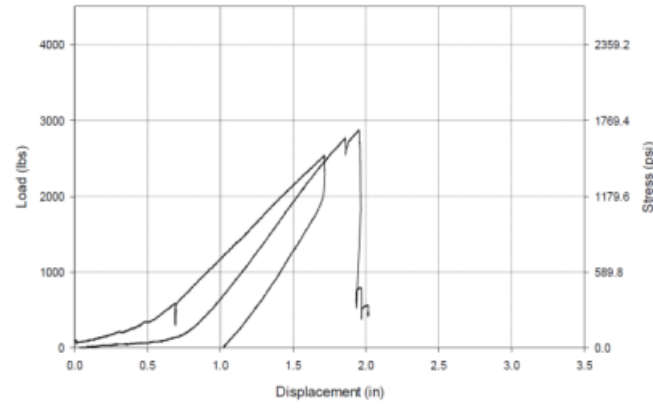

Figure 2. Load-displacement curve of specimen 1SR-S-0: experiment

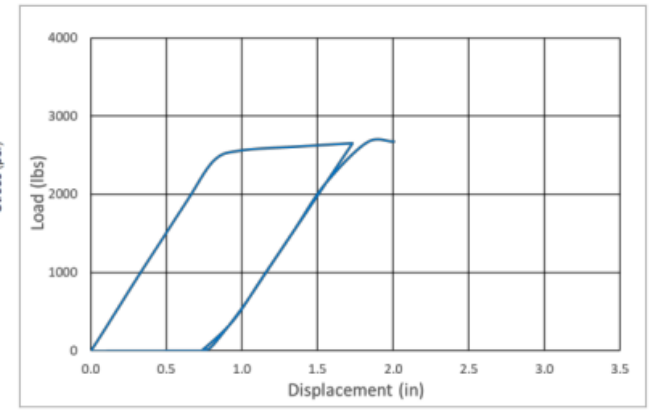

Figure 3. Load-displacement curve of specimen 1SR-S-0: analytical

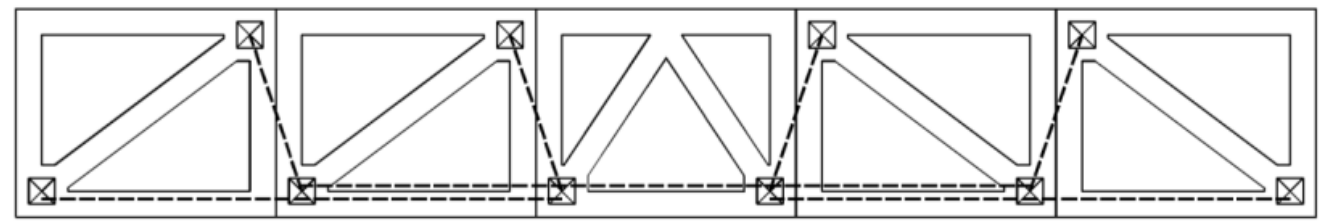

Figure 4. Segmented 3DCP structural beam (adopted from [9]).

3.2 Segmented 3DCP structural beam (non-prestressed connection)

One approach to avoid the weakening problem of the bonding strength, is by printing 3DCP structural members in segments. Making smaller segments reduces the complexity of printing process that consistency of the quality is easier to maintain. Asprone et al. [9] constructed concrete beam from 3DCP segments and conducted bending test. However, the connections needed to assemble the segments raises other challenges. In this case, some hollows in the segments should be made for this connection purpose (see figure 4). Dashed lines in figure 4 represent tension steel bars used to connect the segments. Tension bars mechanically connected and secured with wet joint were used for the connection system. Result of the bending test is presented in figure 5. It was reported that the beam behaved linearly at initial stage (when everything was still intact, with no cracks). But this state was only observed in the very start of the test that it rapidly entered non-linear stage (start of cracking stage, progression of cracking stage, final failure stage). The linear stage (line OA) is comparable with conventionally casted RC beams. But the non-linear stage (line ABC), stiffness reduced quite significantly, not because of degradation of material or wrong optimization but mainly because of the non-effective interface/connection system (the 
connected segmental system is prone to local damages). This shows that the printed concrete quality may be improved, but the connection system introduces different kind of weakening.

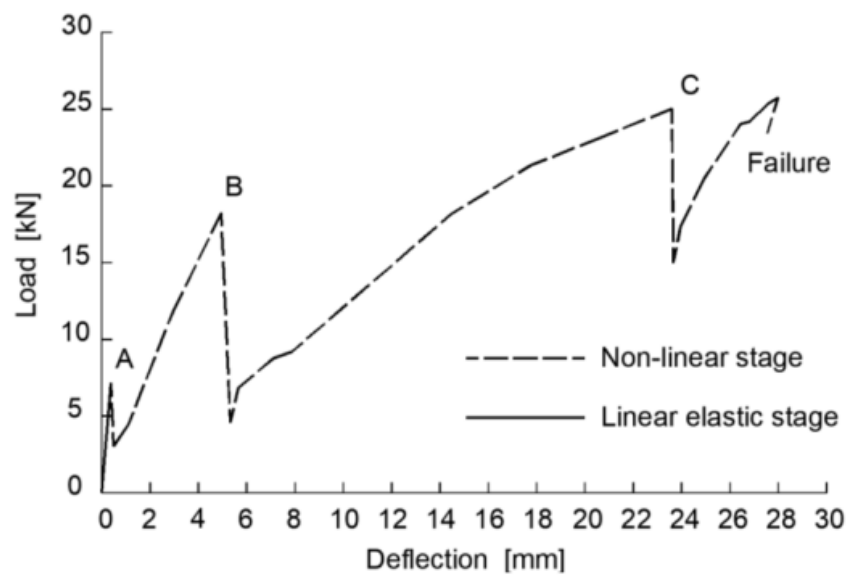

Figure 5. Linear elastic and non-linear stages of load-deflection curve of the beam (adopted from [9]).

\subsection{Segmented 3DCP structural beam (prestressed connection)}

For segmented 3DCP structural beam to work, the connection system may be improved by using posttensioning approach. Vantyghem et al. [10] presented prestressed concrete beam design based on topology optimization and manufacturing process with concrete extrusion technology. The illustration of the beam segments and its reinforcement as well as post tensioning tendons is presented in figure 6 . Due to the symmetric geometry, only half span of the beam is drawn. Bending test was performed on the manufactured beam to record the load-displacement relationship of upper and bottom chords of the beam. The goal was to verify the service load performance of the optimized shape. A finite element analysis of the beam was also conducted and compared to experimental results.

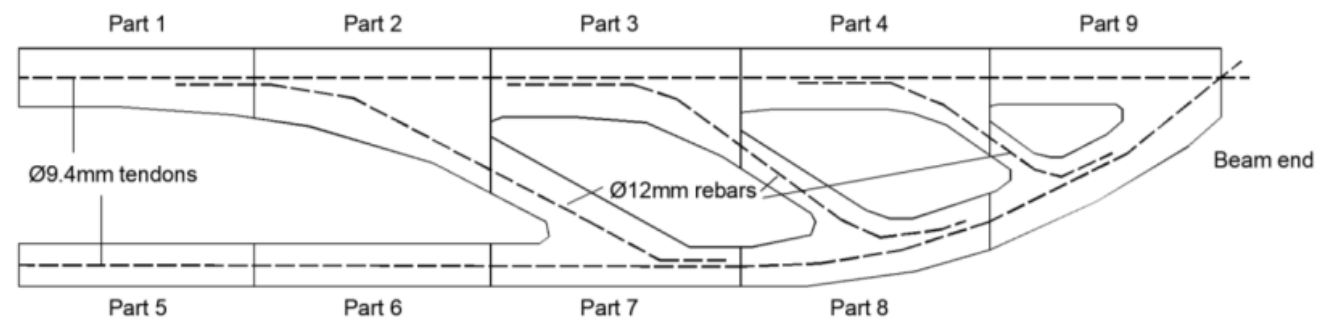

Figure 6. Illustration of the segmented 3DCP structural post tensioned beam (adopted from [10])

Results of the bending test is presented in figure 7. The upper chord showed a good fit (Figure 7a) between the experimental and numerical results. On the other hand, the lower chord shows a much higher deviation (Figure 7b) from the numerical result. Vantyghem et al. stated that this can be attributed to tolerances in the position of the post-tensioning strand within the lower chord, as well as to the sectional assembly. In larger structures, the positioning of the post-tension strand should be easier to control and eliminate this problem. Another factor of uncertainty is the determination of the equivalent material characteristics of the hybrid structure (3DCP segments and grout infill). 


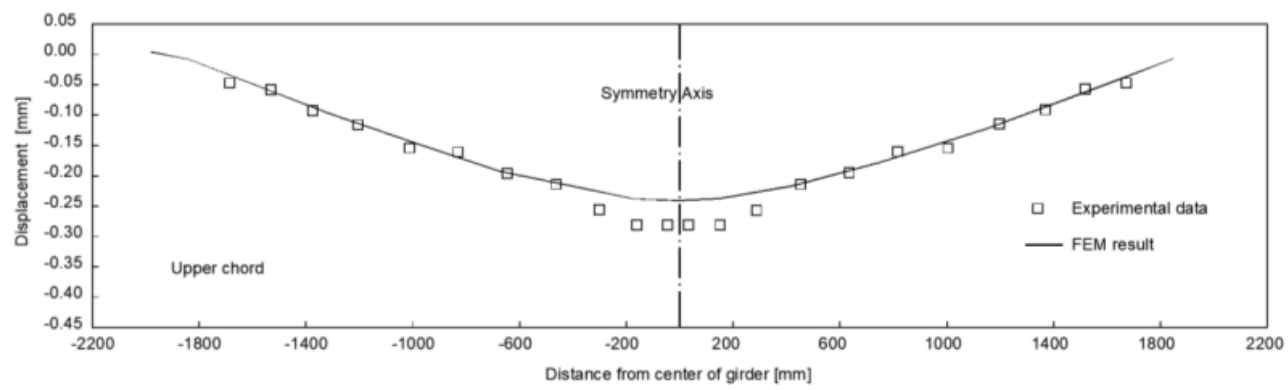

(a)

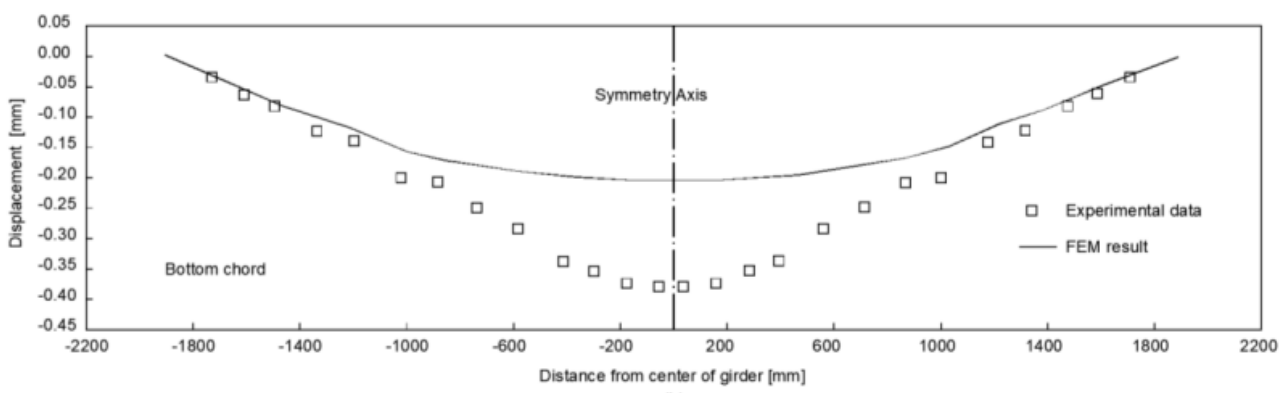

(b)

Figure 7. Force-Displacement of upper and bottom chord (adopted from [10]).

\section{Discussions and concluding remarks}

Reviewing some works by others as well as conducting numerical analysis regarding the use of 3DCP as structural beam members, some discussions and conclusions can be drawn:

- Due to its manufacturing complexity, hardened properties of 3DCP which is commonly assessed by using small specimens, may not be enough for predicting 3DCP structural member behaviour. As a structural member, 3DCP possesses many things to be considered beside of the material hardened properties, that can contribute to its overall behaviour, mainly due to nonhomogenous condition introduced by the printing process.

- To overcome weak points introduced by printing large complex shapes, assemblage approach of smaller 3DCP segments are usually taken. Post-tensioning approach to connect the segments is proven to be quite successful. However, in other point of view, assemblage approach is a little bit contradictory to the initial concept of $3 \mathrm{D}$ printing which gain its popularity from its one step manufacturing process.

\section{cknowledgments}

The authors are grateful for the funding provided by the Deputy for Research Empowerment and Development, Ministry of Research and Technology/National Research and Innovation Centre, Republic of Indonesia under PDUPT scheme no. 002/SP2H/LT-MULTI/LL7/2020.

\section{References}

[1] Schutter G D, Lesage K Mechtcherine V Nerella V N Habert G and Agusti-Juan I 2018 Vision of 3D printing with concrete - technical, economic and environmental potentials Cem. Concr. Res. $11225-36$ 
[2] Gosselin C, Duballet R Roux P Gaudillière N Dirrenberger J and Morel P 2016 Large-scale 3D printing of ultra-high performance concrete - a new processing route for architects and builders Mater. Des. 100 102-9

[3] Wrangler T et al 2016 Digital concrete: opportunities and challenges RILEM Tech. Lett. 1 67-75

[4] Valkenaers H, Jansen D Voet A Gysel A V and Ferraris E 2014 Additive manufacturing for concrete: a $3 \mathrm{~d}$ printing principle Proceedings of the $14^{\text {th }}$ euspen international conference 1139 42

[5] Ma G, Li Z and Wang L 2018 Printable properties of cementitious material containing copper tailings for extrusion based 3D printing Constr. Build. Mater. 162 613-27

[6] Kazemian A, Yuan X Cochran E and Khoshnevis B 2017 Cementitious materials for constructionscale 3D printing: laboratory testing of fresh printing mixture Constr. Build. Mater. $145639-47$

[7] Le T T, Austin S A Lim S Buswell R A Law R Gibb A G F and Thorpe T 2012 Hardened properties of high-performance printing concrete Cem. and Conc. Res. 42 558-66

[8] Al-Chaar G K, Stynoski P B and Banko M L 2018 Structural behavior of layer-printed reinforced concrete beams The Op. Const. and Build. Tech.J. 12 375-88

[9] Asprone D, Auricchio F Menna C and Mercuri V 2018 3D printing of reinforced concrete elements: technology and design approach Const. and Build. Mat. 165 218-31

[10] Vantyghem G, Corte W D Shakour E and Amir O 2020 3D printing of a post-tensioned concrete girder designed by topology optimization Auto. in Const. 112 1-11 
Review on 3D printed concrete as structural beam members

ORIGINALITY REPORT

1.

SIMILARITY INDEX
$1 \%$

INTERNET SOURCES
$1 \%$

PUBLICATIONS
$0 \%$

STUDENT PAPERS

PRIMARY SOURCES

1 link.springer.com Internet Source

2

Guowei Ma, Junfei Zhang, Li Wang, Zhijian Li, Junbo Sun. "Mechanical characterization of 3D printed anisotropic cementitious material by the electromechanical transducer", Smart Materials and Structures, 2018

Publication

Exclude quotes

On

Exclude bibliography
Exclude matches

$<1 \%$ 